\title{
La restauración del claustro de la Catedral de Barcelona: recuperar el vínculo entre arquitectura, vegetación y agua
}

\author{
Victoria Bassa Garrido ${ }^{a}$ y Roser Vives de Delàs ${ }^{b}$
}

${ }^{a}$ LIQUEN Patrimonio y Paisaje, Maternitatd'Elna 6, 08035 Barcelona. victoriabassa@liquenben.com. ${ }^{b}$ LIQUEN Patrimonio y Paisaje, Maternitatd'Elna 6, 08035 Barcelona. roservives@liquenbcn.com

\begin{abstract}
Resumen
Los claustros, a menudo espacios de transición entre el interior y el exterior del templo, y, de forma especial en la Catedral de Barcelona, claramente vinculado a la ciudad, fueron en su momento el centro vital de estos conjuntos patrimoniales. Cualquier intervención en un espacio central ajardinado de esta categoría ha de conseguir que no se desvincule del edificio, que se lea de forma conjunta al mismo, como espacio vertebrador, complementario y por ello único, tal y como fue concebido. La fragilidad de dichos espacios es elevada, principalmente por el carácter dinámico de su propia naturaleza. Son espacios proclives al abandono, e incluso a la segregación ya sea por la modificación de usos, por desconocimiento o por pérdida de interés. La protección patrimonial debe incluir y valorar estos espacios abiertos, que complementan a los monumentos, los contienen o los acompañan de forman indisoluble. Más allá del disfrute tradicional de los sentidos en un espacio ajardinado, como sociedad se valoran ahora también los espacios verdes en términos de calidad de vida: de salud y bienestar, como espacios de espiritualidad y de paz, como espacios donde desarrollar una dimensión artística y cómo no, como parte del compromiso con un mundo más sostenible.
\end{abstract}

Palabras clave: claustro, patrimonio, paisaje, arquitectura, vegetación, agua, huerto, cementerio, espiritualidad, sostenibilidad.

\begin{abstract}
Cloisters are often transition spaces between the interior and exterior of the temple, and, especially in the Cathedral of Barcelona, clearly linked to the city, were once the vital center of these heritage sites. Any intervention in the garden of a central space of this category must ensure that it does not dissociate itself from the building, that it is read together with it, as a vertebral, complementary and therefore unique space, as it was conceived. The fragility of these spaces is high, mainly due to the dynamic process of their own nature. They are spaces prone to abandonment, and even to segregation, whether due to modification of uses, ignorance or loss of interest. The heritage protection must include and value these open spaces, which complement the monuments, contain them or accompany them in an indissoluble way. Beyond the traditional enjoyment of the senses in a garden space, society also values now green spaces in terms of quality of life: health and well-being, as spaces of spirituality and peace, as spaces where to develop an artistic dimension and of course, as part of the commitment to a more sustainable world.
\end{abstract}

Keywords: cloister, heritage, landscape, architecture, vegetation, water, orchard, cemetery, spirituality, sustainability. 


\section{Introducción}

El proyecto de restauración del claustro de la Catedral de Barcelona responde a la necesidad de analizar este espacio en la actualidad, profundizar en su largo recorrido histórico, su protagonismo indiscutible en el conjunto patrimonial de la Catedral y su evolución en cada uno de los diferentes periodos de la historia que lo contemplan (Fig. 1). Se pretende recuperar y visibilizar la importancia del conjunto en cuanto a su arquitectura y decoración escultórica, su vegetación (estudio profundizado del estado actual y la posible recuperación de especies) y el agua (las fuentes, la balsa, las ocas, analizando la presencia y el uso del agua en este espacio) y analizar el uso más adecuado de dicho espacio en relación al turismo diario, masivo, en el que deben equilibrarse la sobreexplotación y el uso frente a la capacidad de carga del monumento y de su protección patrimonial, sin olvidar la relación intrínseca del patrimonio arquitectónico con el patrimonio natural.

El proyecto general de restauración se ha dividido en cuatro grandes capítulos, el estudio histórico, el análisis y diagnóstico del estado actual, los trabajos arqueológicos, su seguimiento y conclusión, La recopilación de datos e investigaciones permitirá establecer las bases y punto de partida para proponer, por último, la intervención de recuperación y adecuación de este espacio claustral de máximo interés, con la voluntad de trabajar con y desde criterios de sostenibilidad en todos los sentidos y con la máxima transversalidad.

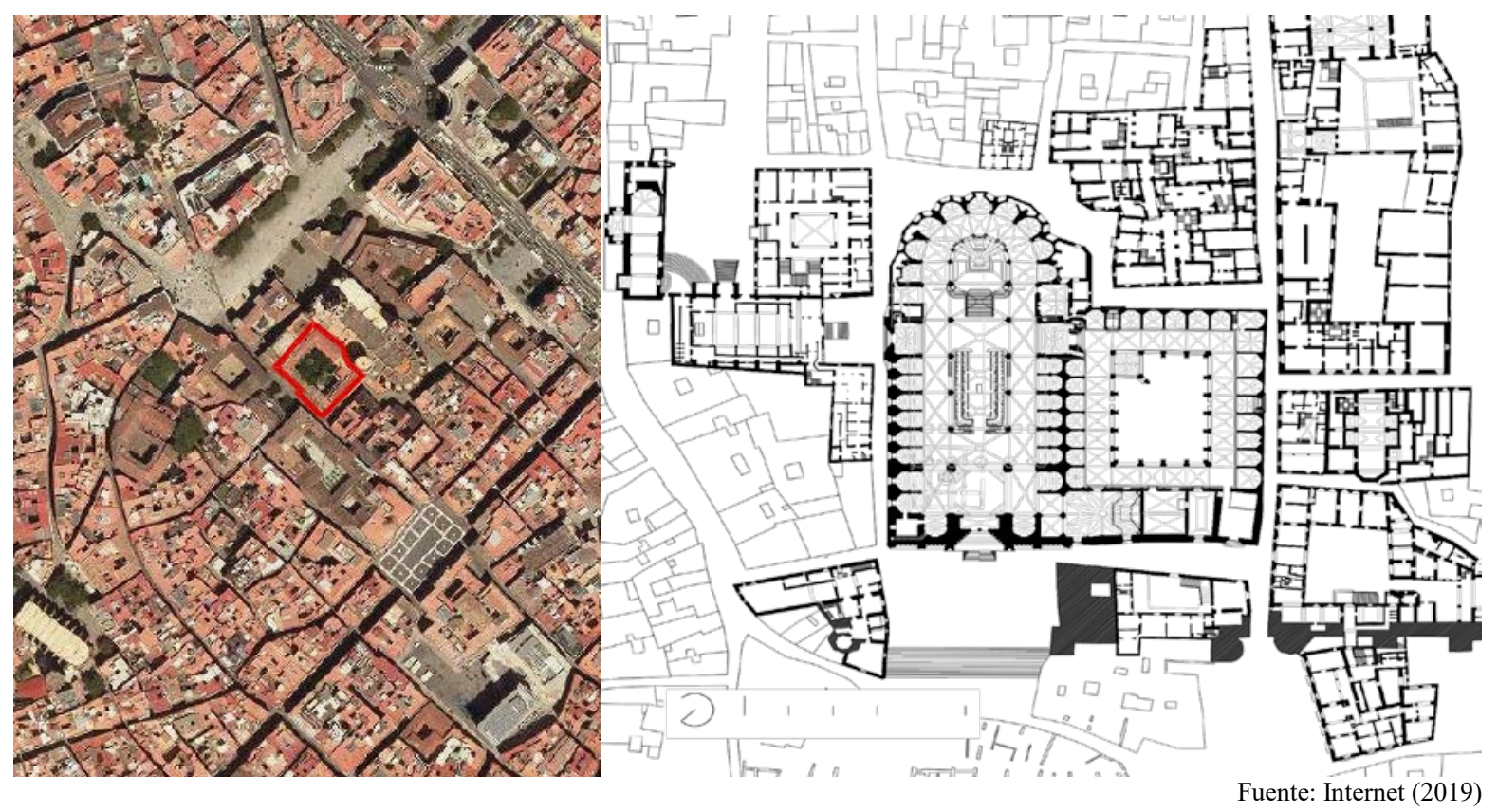

Fig. 1 Imagen aérea de la ciudad de Barcelona y planimetría del Barrio de la Catedral s.XVIII, artículo "De Derecha a Izquierda"de A.J.Marin (Marín, 2010)

\section{Estudio histórico}

\subsection{Contexto histórico}

Antes de adentrarse en la documentación de archivo y de la investigación histórica propiamente dicha vale la pena poner en contexto el jardín medieval y dar una pincelada sobre cómo eran concebidos estos espacios.

En el jardín medieval del Occidente cristiano (Fig. 2) se diferencian dos tipologías principalmente: el jardín monacal y el jardín cortesano. El jardín monacal se desarrolla en los claustros de los monasterios y su esplendor va ligado a la fortuna de los monasterios. Tomaba todo el carácter simbólico del Jardín del Paraíso con la fuente, dividido en cuarterones por los cuatro ríos, el árbol sagrado, la relación con el Divino, en definitiva un espacio de contemplación. Si 
existía más de un claustro, el jardín seguía siendo cerrado y a menudo formalmente dividido en cuatro donde se cultivaban plantas medicinales, aromáticas, condimentarias y de flor.

El jardín cortesano tiene a menudo más complejidad que el monacal, con más espacios pero de igual factura compositiva.

El jardín islámico aparece contemporáneamente al jardín medieval occidental, a partir del s.VII, cuando se consolida el islamismo como fuerza política. Su influencia en el sur de la península va desde el 712 al s. XV en que cae Granada (Ribas, 1991).
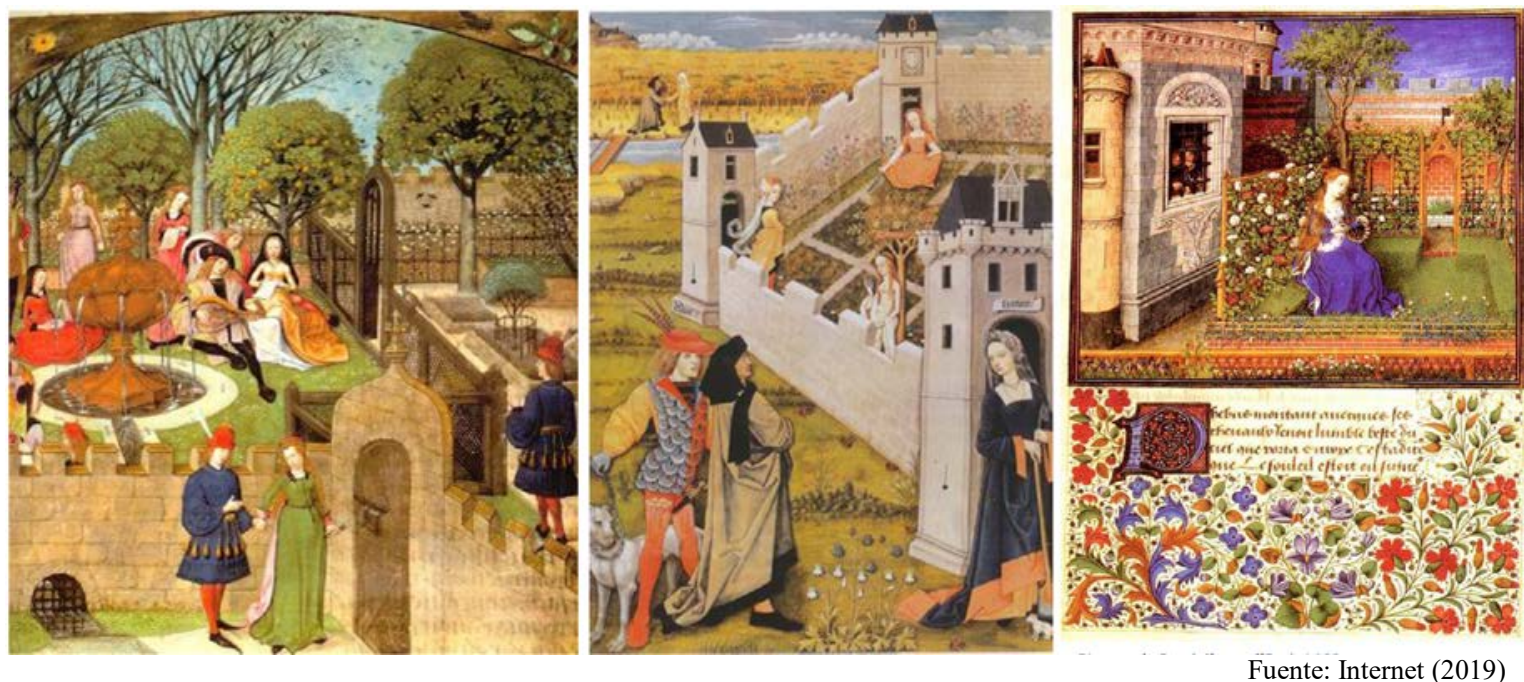

Fig. 2 Le Verger de Déduit, del Roman de la Rose de Guillaume de Lorris et Jean de Meun, 1500circa. British Librery,

London, pintado por Robinet Testart 1496-98, Le livre des Echecs amoureux. Evrard de Conty, pintura de

Barthélemyd'Eych 1460 ca. y Emilia en el jardín del castillo de Tebes. Teseida de Boccaccio. Biblioteca nacional austríaca. Viena

Catalunya tiene jardines monacales de gran importancia como son los Claustros de Poblet y Santes Creus y, principalmente el del Monasterio de Pedralbes (Fig. 3), en la misma ciudad de Barcelona.

El estudio más detallado nos permite ir más allá de lo que a menudo y únicamente se describe como jardín medieval monacal en relación al jardín del Paraíso y a la división en cuarterones para diferentes tipos de cultivos. Si bien esta división formal es una característica muy común tanto en jardines monacales como en cortesanos, el tratamiento de la vegetación era diferente según el caso concreto. Unos claustros tenían naranjos, otros flores, otros hierbas medicinales y otros eran huertos propiamente dichos.

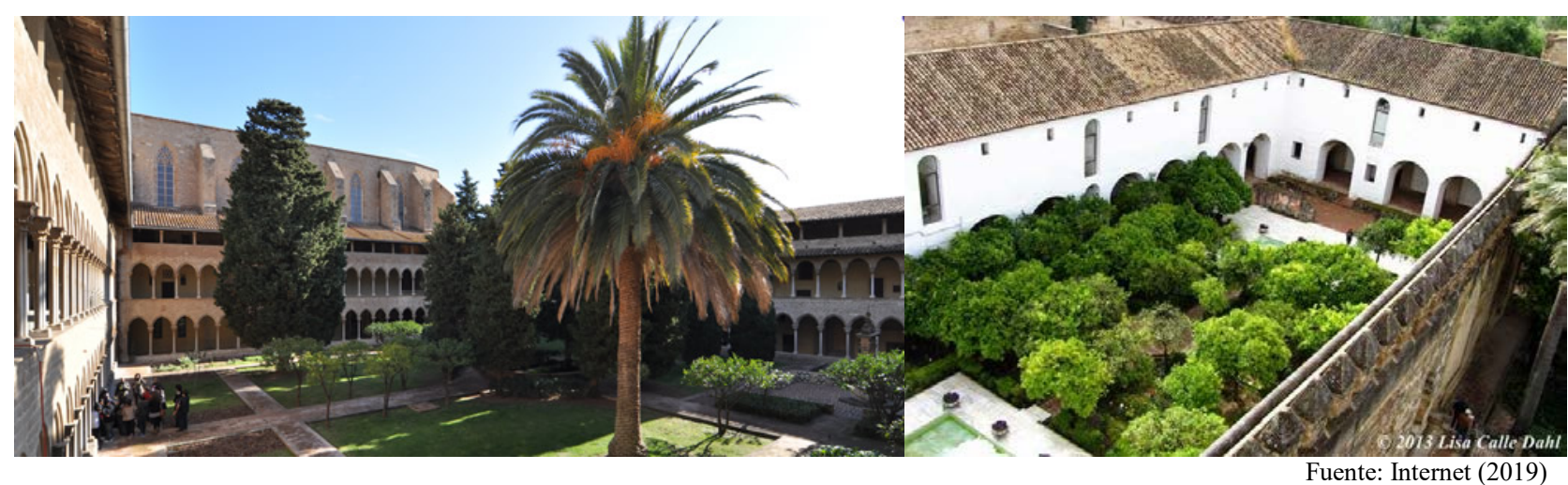

Fig. 3 Imagen del Claustro del Monasterio de Pedralbes, Barcelona y del patio morisco del Alcázar de los Reyes, Córdoba

En los conjuntos catedralicios, sin comunidad asociada, el Claustro tomaba el valor simbólico de relación con Dios, pero para toda la feligresía, que por aquel entonces significaba que era para todo el mundo. A menudo eran también 
cementerios como es el caso de Barcelona y entonces se acostumbraba a plantar frutales, sería lo que podríamos llamar de forma más apropiada un vergel: vergel-cementerio.

Eran el espacio de conexión entre el templo y la trama urbana, espacio de paseo habitual para visitar a los difuntos y dónde se celebraban la mayor parte de las fiestas relacionadas siempre con el calendario religioso (Amat, 1750-1819).

A pesar de que en Catalunya no hay ningún jardín de confección árabe, su influencia seguro que llegó igualmente ya que la relación era intensa. Hay bellos ejemplos en Mallorca y Valencia y se ve por ejemplo en las cartas escritas por el Rey Martín el Humano en las que se puede leer su gran admiración por la vegetación, naranjos, limoneros, jazmines, mirtos, etc., característicos de estos jardines, así como la influencia que tuvieron en él los jardines del Real de Valencia donde pasó largas temporadas. El estudio de su epistolario es la fuente que da detalles y referencias varias del Vergel del Palacio Real Mayor, vecino del claustro de la Catedral y creado en la misma época (Adroer, 1975).

\subsection{Investigación de archivo: Arquitectura, vegetación y agua}

La documentación archivística investigada recoge todas las fuentes históricas consultadas de la ciudad de Barcelona, todos los protagonistas que describieron el Claustro, que lo dibujaron, lo pintaron y lo fotografiaron. Se han analizado en profundidad todos los documentos para conocer cómo fue y cómo evolucionó este espacio: los elementos que lo conforman, su origen, el uso al que eran destinados y los cambios sufridos para adaptarse a las diferentes necesidades a lo largo de los siglos (Laborde, 1474-1974).

Por otro lado, en una labor en realidad no acabada, se han extraído muchos datos de los libros del Archivo Catedralicio (Fig. 4) que documentan con todo detalle y en perfecto orden cronológico todas las actuaciones relacionadas con las obras, y con el cuidado y mantenimiento de la Catedral y el Claustro (Libros de Obres de la Seu, 1421-1817).
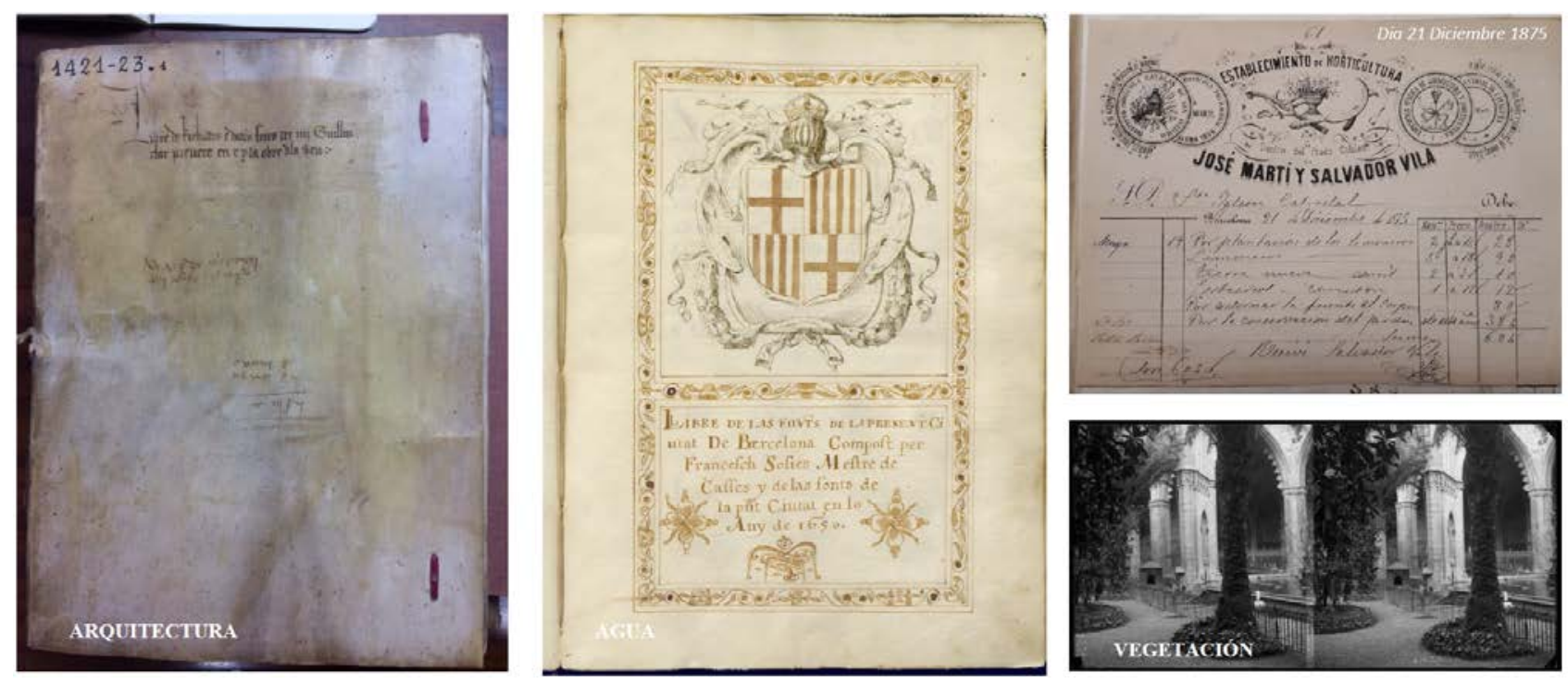

Fuente: Archivo Catedralicio y Centro Excursionista de Catalunya (2019)

Fig. 4 Portada del libro de obras del Archivo Capitular de la Catedral (1421-1423), portada del libro de las fuentes de la ciudad de Barcelona (1650), recibo detrabajos de horticultura (1875) del Libro de cuentas (1868-1880) del Archivo Capitular y fotografía del claustro (1888) del Centro Excursionista de Catalunya

Cruzando todas las fuentes investigadas se ha querido diferenciar en el estudio los aspectos relacionados con la arquitectura del claustro, la vegetación y los elementos relacionados con el agua, dando igual importancia a cada uno de estos elementos con el objetivo de poner en relieve la interacción y buena harmonía entre ellos en el diseño original.

\subsubsection{Evolución arquitectónica del Claustro}

El claustro de la Catedral de Barcelona, de estilo gótico, es un espacio único de una fuerza y belleza extrema que articula, configura y complementa uno de los edificios religiosos más importantes de la ciudad. Se conoce de su 
existencia en época románica como lo atestigua una documentación del 1078 y por las descripciones de la capilla del gremio de los Zapateros y otros, aunque se desconoce el aspecto inicial del mismo. En la construcción del claustro gótico, entre los siglos XIV y XV, participaron diferentes maestros de obras destacando Andreu Escuder y los escultores Claperós, padre e hijo (Carreras, 1914). El claustro era principalmente un espacio destinado a enterramientos.

Geométricamente el claustro es un espacio cuadrangular de $62 \times 44$ metros con 21 capillas laterales distribuidas siete a cada lado del espacio. La primera galería del claustro construida fue la más cercana a la basílica, mientras que la galería que da a la calle del Bisbe fue la última en construirse. En tres de sus galerías hay capillas, que al principio estaban bajo la advocación del patrón de alguna institución o gremio, o bien eran panteón de alguna familia.

Destacan los trabajos escultóricos de los capiteles del claustro (Fig. 5), con escenas del Antiguo Testamento presentes en los pilares de los arcos del claustro y del Nuevo Testamento en las claves de bóveda, todo el conjunto como una representación de la «Historia de la Salvación». Los detalles escultóricos de las columnas de los arcos ojivales tienen la leyenda del Árbol de la Santa Cruz, que Duran y Sanpere describe (Duran, 1952) y sobre la que hace una interesante interpretación.
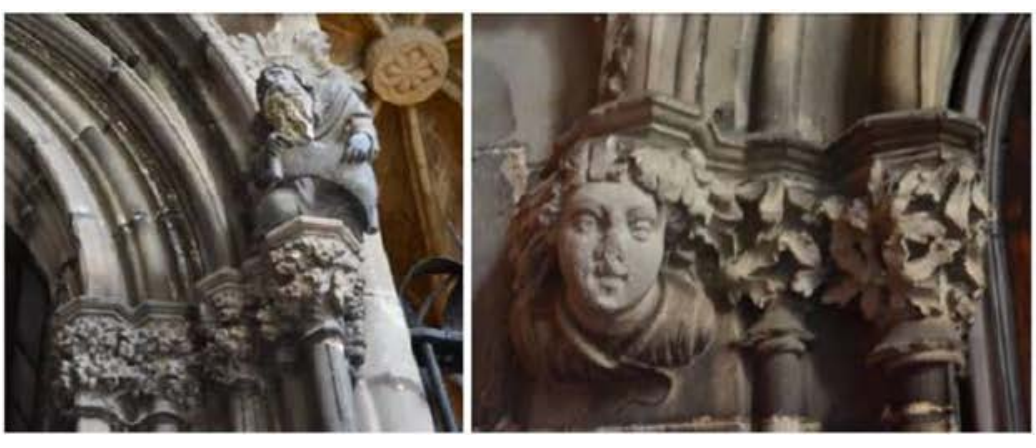

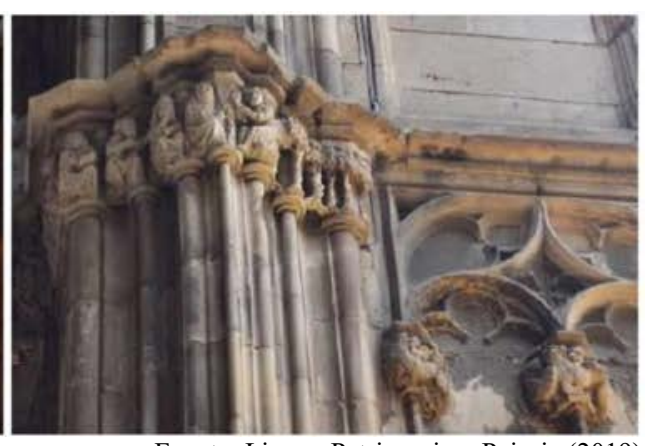

Fuente: Liquen Patrimonio y Paisaje (2019)

Fig. 5 Detalles de los trabajos escultóricos sobre puertas y en capiteles del claustro de la Catedral

Unos de los elementos a destacar también y que a menudo pasan más desapercibidas son las rejas que cierran las capillas del claustro (Ainaud, 1947) que son de manufactura antigua, mayoritariamente del s. XV y muestran el gran trabajo en la forja artesana de la época. Las rejas en los arcos ojivales hacia el jardín, son posteriores y diseñadas en 1866 por Josep Oriol Mestres.

Actualmente, el Claustro presenta patologías principalmente derivadas de la contaminación ambiental que ha recubierto este espacio con una pátina gris y está provocando alteraciones en la piedra. Los cambios de nivel del interior del jardín han provocado filtraciones puntuales en cerramientos. Las losas de los vasos funerarios (actualmente desocupados) sufren el desgaste de su uso diario, en las galerías perimetrales.

En términos generales y pese al deterioro descrito podemos decir que desde el punto de vista arquitectónico el claustro de la Catedral de Barcelona se conserva tal y como fue.

\subsubsection{Evolución del jardín}

El estudio de las diferentes fuentes y bibliografía consultada nos muestran como la presencia de naranjos (Fig. 6), limoneros, cipreses ya está documentada en 1494 y es constante a lo largo de los siglos sin apenas variaciones. Su cuidado, mantenimiento y reposición es constante a lo largo de los siglos hasta la remodelación completa del jardín en 1877 al estilo de la época, con magnolias, palmeras y parterres elevados (Bassegoda, 1995). Las magnolias son hoy en día ejemplares centenarios y catalogados. Han sobrepasado la altura del claustro y han hecho del recinto un espacio de sombra completamente distinto al jardín original. 

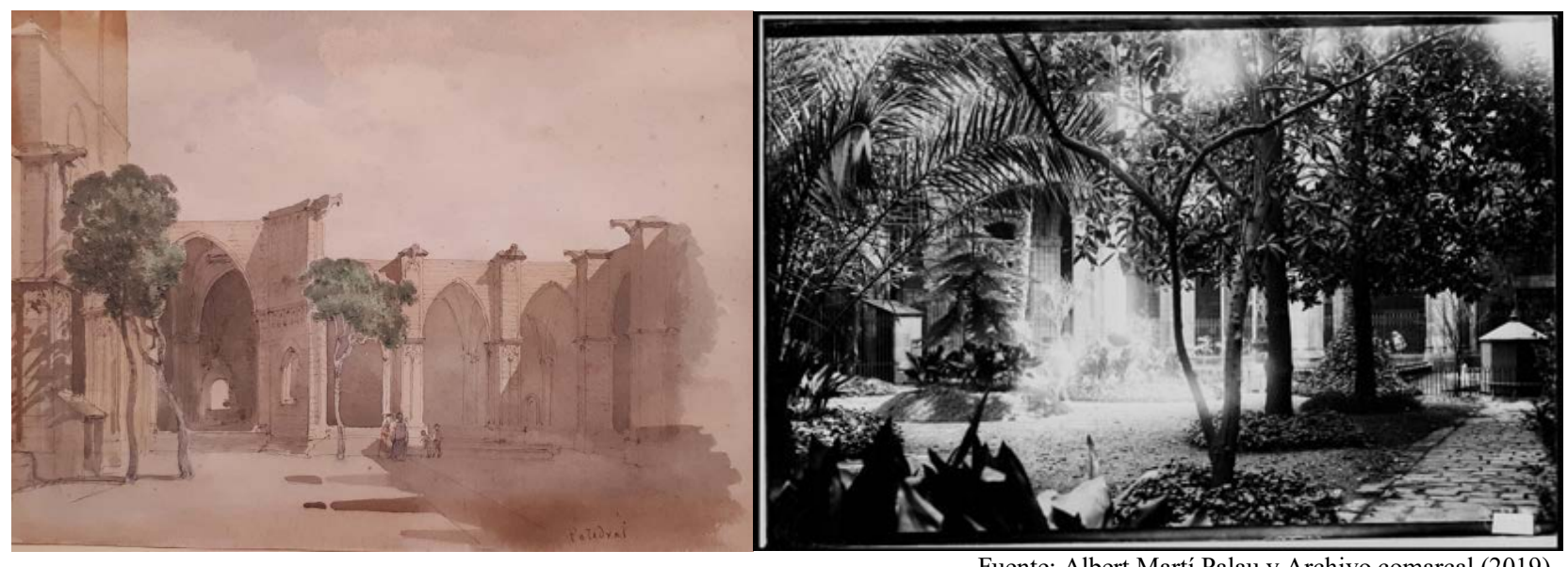

Fig. 6 Dibujo de Luis Rigalt Ferriols (1860) e imagen del claustro (1915)

También se pone de manifiesto la presencia de ocas (Fig. 7) y varias aves a lo largo de la historia, ya documentadas en 1480, tanto por la referencia a la compra de animales como por el suministro de comida para las mismas.

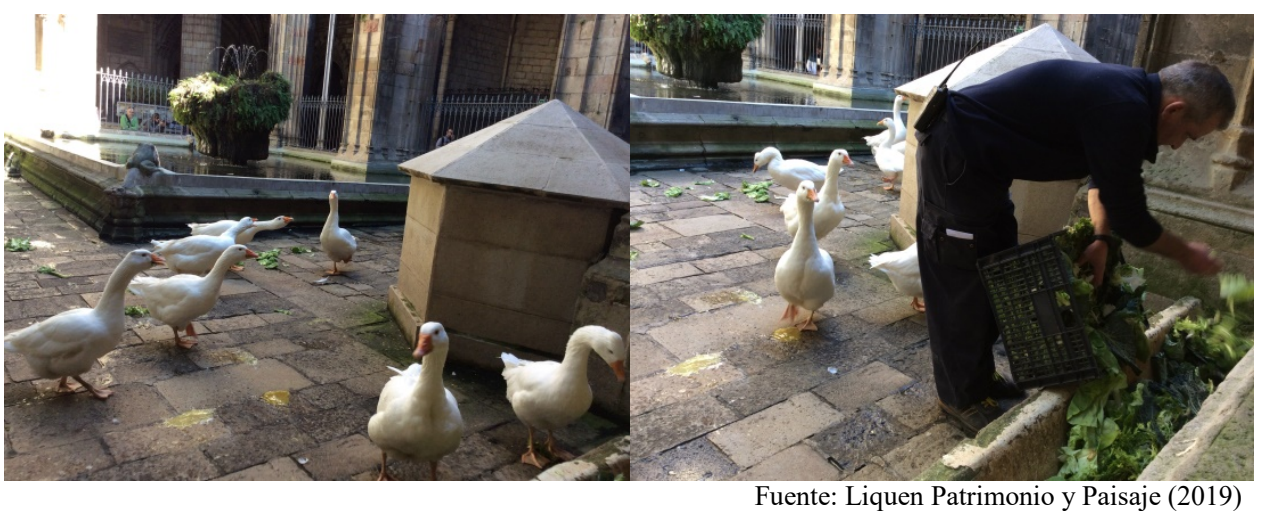

Fig. 7 Imágenes de las ocas del claustro

\subsubsection{Evolución de los elementos de agua}

La balsa de las ocas (Fig. 8) y la fuente de Sant Jordi (Fig. 10) son dos elementos característicos y muy representativos en el claustro. La balsa aparece ya referenciada desde los inicios del nuevo claustro gótico. No hay prácticamente ninguna descripción arquitectónica de la misma en las fuentes consultadas.

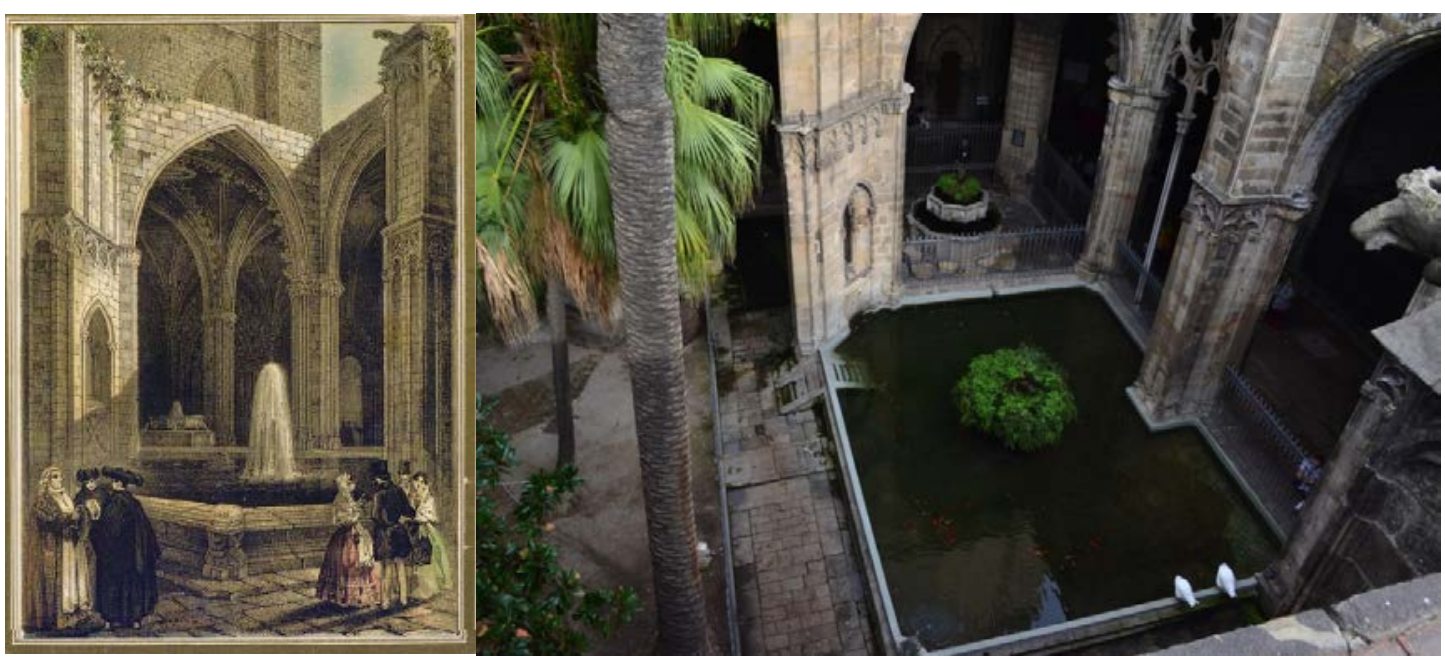

Fuente: Grabado, Archivo Ayuntamiento Barcelona e imagenLiquen Patrimonioy Paisaje (2019)

Fig. 8 La balsa según el dibujo J.Parcerisa. 1839-41, Archivo Ayuntamiento de Barcelona e imagen actual de la misma 
La información recogida del archivo catedralicio, así como el trabajo de investigación y la transcripción del Llibre de les Fonts de la ciudad de Barcelona del maestro Socies (Fig. 4), en el que describe milimétricamente la distribución del agua dentro de la Sede. Describe también su intervención en 1621 cuando realiza la obra de los nuevos repartidores y el nuevo recorrido de las tuberías del surtidor mayor y de la balsa. Detalla y enumera, en lugares estratégicos del recorrido, la presencia de una serie de cruces esculpidas en varias zonas del claustro (Fig. 9) - como en la fachada junto acceso a la capilla de Santa Lucíaen el pretil del jardín o en el cierre de la Fuente de San Jordi, entre otros- como marcas del recorrido de las tuberías. Se ha podido comprobar que estas cruces efectivamente existen aún hoy en día tal y como el maestro Socies describe detalladamente (Socies, 1650).
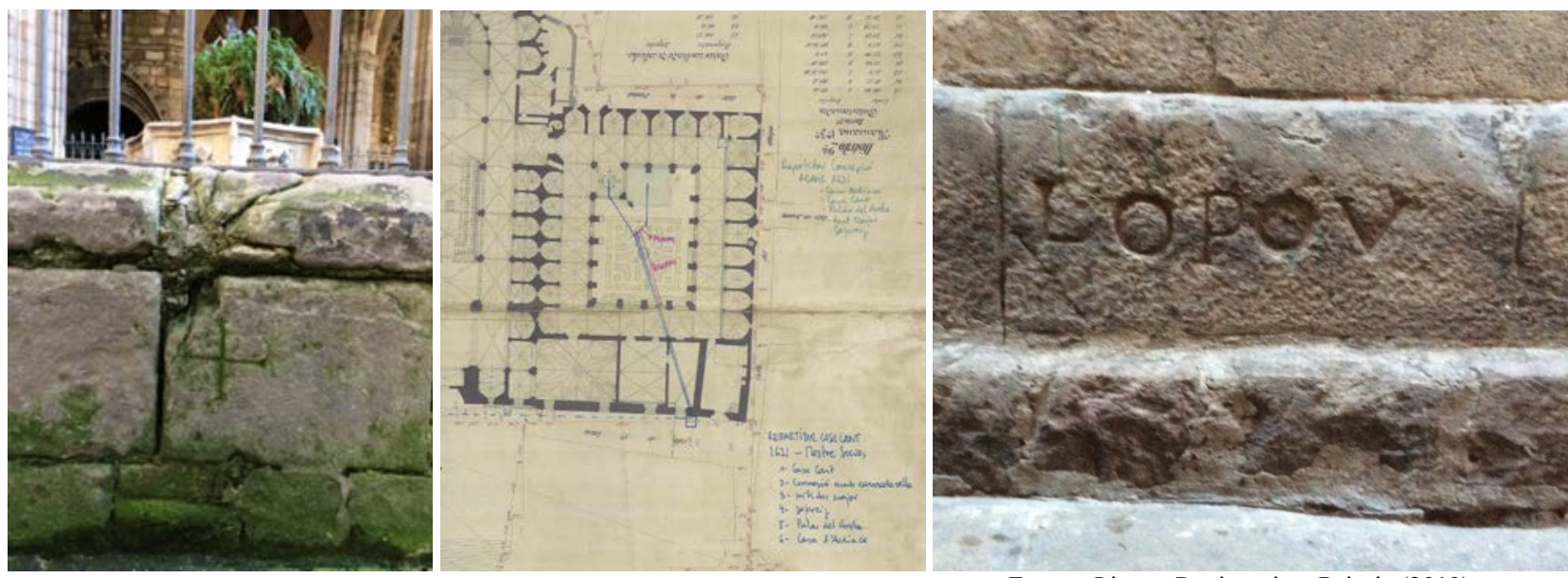

Fuente: Liquen Patrimonio y Paisaje (2019)

Fig. 9 Imágenes de las cruces en paramentos del claustro y reproducción esquemática, con conversión a canas y palmos del manuscrito del maestro Socies sobre la distribución del agua antes y después del 1621

La fuente de Sant Jordi (Fig. 10), se construyó en el año 1448, en substitución de una anterior. Se cubrió de una bóveda de crucería soportada por un gran pilar en diagonal. Fue construida por el maestro de obras Escuder con una clave de bóveda con la escena de Sant Jordi, obra de los escultores Antonio y Juan Claperós. La escultura de Sant Jordi que actualmente decora el surtidor fue realizada por Emilio Colom en 1970.

Durante las fiestas del Corpus en Junio dicha fuente se decora con flores y se realiza el "OucomBalla", siguiendo la misma tradición desde hace siglos, tal y como queda recogido en la documentación del archivo de la Catedral (Martí, 2010).
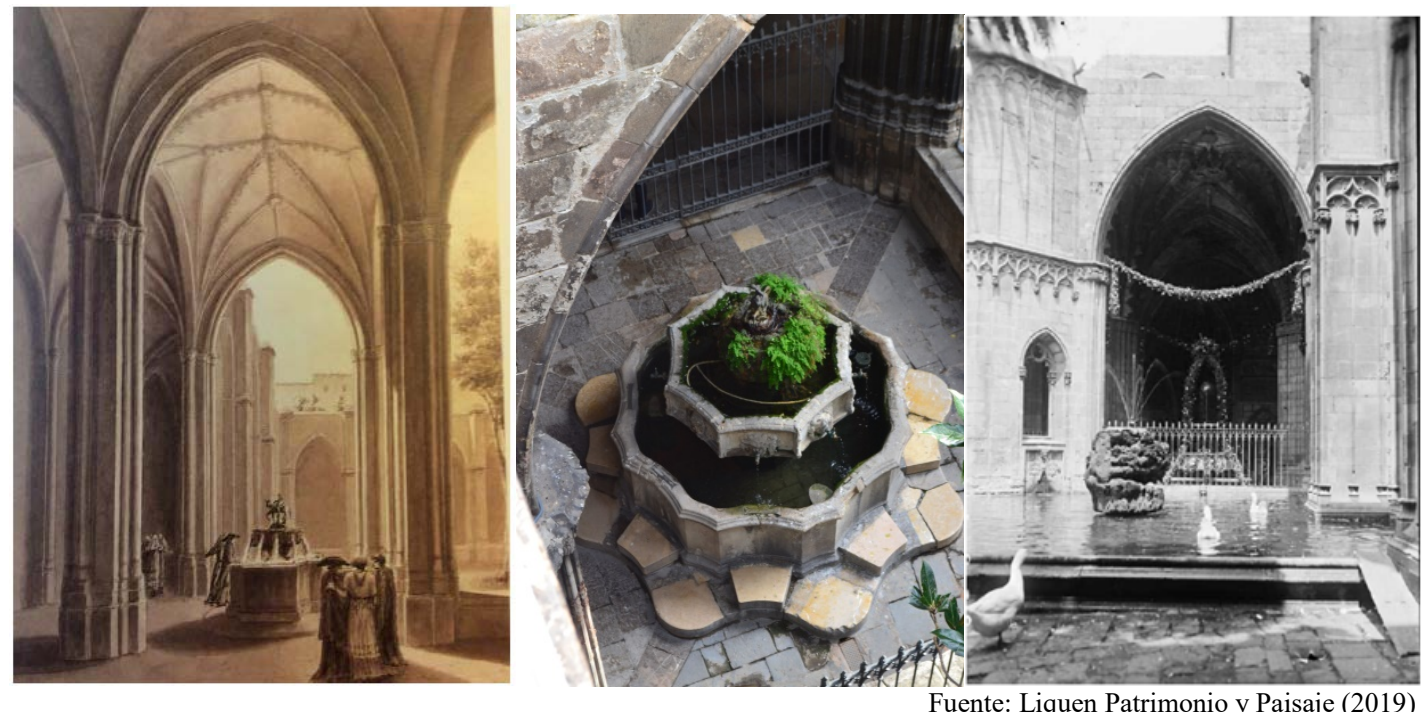

Fuente: Liquen Patrimonio y Paisaje (2019)

Fig. 10 Fuente de Sant Jordi según el dibujo del libro de los viajes de Alexandre Laborde. Francia (1801-1803), imagen actual de la fuente e imagen de la misma en 1929 


\section{Conclusiones}

El Claustro de la Catedral de Barcelona ha tenido a lo largo de los siglos y en función de los acontecimientos de la historia, periodos de bonanza y de penuria, siendo siempre eje vertebrador entre el espacio de culto de la Catedral y la Ciudad. Ha sido un espacio concurrido, donde la vida social y las fiestas relacionadas con el calendario religioso tenían y siguen teniendo su epicentro.

$\mathrm{Su}$ arquitectura se ha mantenido intacta. El transcurso del tiempo ha dejado una pátina general gris y apagada y se hace evidente el desgaste general del conjunto pero sin desmerecer la majestuosidad volumétrica y la enorme calidad escultórica y de acabados del conjunto.

El jardín del Claustro ha sido durante siglos un jardín de naranjos con algún otro cítrico, cipreses y probablemente alguna palmera datilera. En referencia a las especies arbóreas del jardín, se sabe que en 1494 había naranjos, limoneros y cipreses. La remodelación de 1877 introdujo las magnolias y palmeras exóticas, como las livistonas, que hoy en día tienen valor como ejemplares añejos. Actualmente el jardín presenta serios problemas de decadencia y precisa de un proyecto global que más allá del tema relacionado con la vegetación solucione las instalaciones, la gestión del agua y la compatibilidad con los usos hoy en día requeridos.

El agua en este espacio es un elemento fundacional vital cuyo origen se remonta al 1431. Las fuentes ornamentales están en buen estado de conservación pero el agua debe recuperar su papel protagonista, imprescindible en el Claustro y las ocas seguirán disfrutando de su presencia. Sobre las aves del Claustro se sabe que ya estaban presentes en $1480 \mathrm{y}$ desde 1621 se cita a las ocas y como eran alimentadas diariamente.

El estudio histórico y arqueológico dará las pistas y fundamentos necesarios para la toma de decisiones posteriores en el proceso de restauración del conjunto. Esta restauración es una apuesta por la recuperación patrimonial, por visibilizar mejor su gran potencial y conseguir la transmisión de dichos valores culturales y artísticos con claridad y proximidad hacia el entorno, a través de evidenciar la relación entre arquitectura, vegetación y agua.

\section{Referencias}

Adroer, A. M. (1975). El Palacio real Mayor de Barcelona en época de Martín el Humano (Tesis doctoral Vol 1,Vol 2). Universidad de Barcelona.

Ainaud, J., Gudiol, J., y Verrie, F. P. (1947). Catálogo Monumental de España. La ciudad de Barcelona. Madrid: Centro Superior de Investigaciones Científicas Instituto Diego Velázquez.

Amat, R. (1750-1819). Viles i ciutats de Catalunya. Barcelona: Edició crítica.

Bassegoda, J. (1995). El treball i les hores a la Catedral de Barcelona. Un quart de segled'estudis, projectes i obres. Barcelona: Canuda.

Carreras, F. (1914). Geografia General de Catalunya. La Ciutat de Barcelona. Barcelona: Establiment Editorial Albert Martin.

Duran, A. (1952). La Catedral de Barcelona: itinerarios artísticos. Barcelona: Aymá.

Laborde, A. (1474-1974). Viatgepintorescihistòric. El Principat. Barcelona: Publicacions de l'Abadia de Montserrat.

Libros de Obres de la Seu (1421-1817). Barcelona: Archivo Capitular de la Catedral de Barcelona.

Marín, A. J. (2010). De derecha a izquierda: superposiciones de la Catedral de la Santa Creu i Santa Eulàlia a través del Barrio de ála Catedral (Proyecto Final Máster). Barcelona: Universidad Politécnica de Catalunya.

Martí, J. M. (2010). La Catedral de Barcelona: història i històries: des de la Catedral de Barcelona, cinc minuts a Ràdio Estel: curiositats, costums. Barcelona: Catedral i Museu Diocesà de Barcelona.

Socies, F. (1650). Llibre de les fonts de la presentciutat de Barcelona. Barcelona: Fondo AHCB/CCAM.

Ribas i Piera, M. (1991). Jardins de Catalunya. Barcelona: Edicions 62. 